\title{
The interactive effects of ambient air pollutants-meteorological factors on confirmed cases of COVID-19 in 120 Chinese cities
}

\author{
Jianli Zhou ${ }^{1} \cdot$ Linyuan Qin ${ }^{2} \cdot$ Xiaojing Meng ${ }^{1} \cdot$ Nan Liu $^{1,3,4,5}$ (D) \\ Received: 21 August 2020 / Accepted: 20 January 2021 / Published online: 27 January 2021 \\ (C) The Author(s), under exclusive licence to Springer-Verlag GmbH, DE part of Springer Nature 2021
}

\begin{abstract}
Emerging evidence has confirmed meteorological factors and air pollutants affect novel coronavirus disease 2019 (COVID-19). However, no studies to date have considered the impact of interactions between meteorological factors and air pollutants on COVID-19 transmission. This study explores the association between ambient air pollutants $\left(\mathrm{PM}_{2.5}, \mathrm{NO}_{2}, \mathrm{SO}_{2}, \mathrm{CO}_{2}\right.$ and $\left.\mathrm{O}_{3}\right)$, meteorological factors (average temperature, diurnal temperature range, relative humidity, wind velocity, air pressure, precipitation, and hours of sunshine), and their interaction on confirmed case counts of COVID-19 in 120 Chinese cities. We modeled total confirmed cases of COVID-19 as the dependent variable with meteorological factors, air pollutants, and their interactions as the independent variables. To account for potential migration effects, we included the migration scale index (MSI) from Wuhan to each of the 120 cities included in the model, using data from 15 Jan. to 18 Mar. 2020. As an important confounding factor, MSI was considered in a negative binomial regression analysis. Positive associations were found between the number of confirmed cases of COVID-19 and CO, $\mathrm{PM}_{2.5}$, relative humidity, and $\mathrm{O}_{3}$, with and without MSI-adjustment. Negative associations were also found for $\mathrm{SO}_{2}$ and wind velocity both with and without controlling for population migration. In addition, air pollutants and meteorological factors had interactive effects on COVID-19 after controlling for MSI. In conclusion, air pollutants, meteorological factors, and their interactions all affect COVID-19 cases.
\end{abstract}

Keywords Air pollutants $\cdot$ COVID-19 $\cdot$ Interactive effect $\cdot$ Meteorological parameters $\cdot$ Migration scale index $\cdot$ Negative binomial regression

\section{Highlights}

- A comprehensive study is to explore the effects of both air pollutants and meteorological factors and their interaction effects on COVID-19 confirmed cases with and without controlling population migration.

- COVID-19 confirmed cases and CO, $\mathrm{PM}_{2.5}$, and relative humidity are positively associated.

- $\mathrm{SO}_{2}$ is negatively correlated with COVID-19 confirmed cases.

- The pollutants-meteorological factors interaction effects also associated with COVID-19.

Responsible Editor: Lotfi Aleya

Xiaojing Meng

xiaojingmeng@smu.edu.cn

$\triangle \quad$ Nan Liu

nhyy8132@smu.edu.cn; 13688869875@163.com

1 Department of Occupational Health and Occupational Medicine, Guangdong Provincial Key Laboratory of Tropical Disease Research, School of Public Health, Southern Medical University, Guangzhou 510515, People's Republic of China
2 Department of Epidemiology and Statistics, School of Public Health, Guilin Medical University, Guilin 541001, People's Republic of China

3 Pinghu Hospital, Health Science Center, Shenzhen University, Shenzhen 518116, People's Republic of China

4 Institute of Public Health, School of Nursing, Henan University, Kaifeng 475004, People's Republic of China

5 College of Public Health, Zhengzhou University, Zhengzhou 540001, People's Republic of China 


\section{Introduction}

In Dec. 2019, a novel coronavirus disease (COVID-19) caused by severe acute respiratory syndrome coronavirus 2 (SARS-CoV-2) was reported in Wuhan City, P. R. China (Wu et al. 2020, Zhou et al. 2020). The COVID-19 outbreak rapidly spread across China and to many other countries (Holshue et al. 2020, Huang et al. 2017, Lai et al. 2020, Wang et al. 2020a). Due to its transmissibility and increasing spread, COVID-19 was officially declared a pandemic by the World Health Organization (WHO) on 11 Mar. 2020 (https:// www.who.int/emergencies/diseases/novel-coronavirus2019). By 17 August 2020, COVID-19 had become prevalent in 188 countries, with a total of $21,869,433$ confirmed cases worldwide (https://www.who.int/emergencies/diseases/ novel-coronavirus-2019/situation-reports/); and 89,906 confirmed cases in China (http://www.nhc.gov.cn/xcs/ xxgzbd/gzbd_index.shtml). This has created a worldwide public health crisis.

Air pollutants can significantly affect health and the WHO indicates that 4.6 million individuals die annually from diseases and illnesses directly related to poor air quality (Tobias $\&$ Molina 2020). In particular, increasing numbers of studies suggest a relationship between air pollution and infectious diseases. While previous studies report no relationship between air pollution and SARS outbreaks (Cai et al. 2007, Tobias and Molina, 2020, Yusuf et al. 2007), a positive association was observed between air pollutants (sulfur dioxide, nitrogen dioxide, carbon monoxide, and ground-level ozone) and SARS fatality rates (Cui et al. 2003). Another study in Brisbane suggested that high concentrations of ozone $\left(\mathrm{O}_{3}\right)$ and particulate matter $<10 \mu \mathrm{m}\left(\mathrm{PM}_{10}\right)$ were associated with increased pediatric influenza cases (Xu et al. 2013a).

Meteorological factors are another independent factor that can affect the spread of infectious diseases (Cai et al. 2007, Xie and Zhu, 2020). Although the association between viruses leading to respiratory disease (e.g., SARS, viral influenza and SARS-CoV-2) and meteorological factors has been explored (Yusuf et al. 2007), results of these studies remain controversial. For example, Tan et al. found a sharp change in ambient temperature was correlated with increased risk of SARS, (Tan et al. 2005), while Yao et al. found ambient temperature had no significant effect on the transmissibility of SARS-CoV-2 (Yao et al. 2020). Other studies indicate that an increase in average temperature contributes to an increase in average relative risk (RR) but a decrease in daily confirmed case counts of SARS (Cai et al. 2007). These inconsistent results may reflect an interaction occurring between pollutants and meteorological effects on the transmission of these diseases.

The trends of the SARS outbreak may be influenced by air pollutants and meteorological factors that change host susceptibility and survival time of SARS-CoV in vitro (Cai et al. 2007). COVID-19 infections can cause serious respiratory diseases such as acute respiratory syndrome ( $\mathrm{Du}$ et al. 2020), viral pneumonia (Wu and McGoogan, 2020), and exacerbated inflammatory responses (Mancia et al. 2020). Common symptoms at the beginning of infection include fever, cough, muscle aches, or fatigue, similar to SARS-CoV (Liu et al. 2020b, Siordia Jr., 2020), and an effect of air pollutants and meteorological factors, similar to that seen in SARS, on confirmed COVID-19 cases has also observed (Jiang et al. 2020, Liu et al. 2020a, Oliveiros et al. 2020, Wang et al. 2020b, Zhu et al. 2020); however, the interactive effects of air pollutants and meteorological factors have not yet been considered. Given the human to human transmission of COVID-19, population migration is also likely to be an important confounding factor when evaluating the effects of meteorological factors and air pollutants on COVID-19, and it has been established that COVID19 cases are almost linearly correlated with the number of people traveled from Wuhan to the destination city (Hu Jianxiong et al. 2020). In this study, we investigate the association between ambient air pollutants, meteorological factors, and their interactive effects on the number of COVID-19 confirmed cases while also controlling for population migration effects, to extend and further our understanding of the relationship between transmission of this disease and environmental factors.

\section{Methods}

\section{Data collection}

We observed the numbers of the confirmed cases in relation to air pollutants, meteorological parameters, and the migration scale index (MSI) in 120 Chinese cities covering the majority of mainland China. The MSI reflects the scale of urban migration into or out of the assigned population, using a horizontal comparison among cities to reflect the trend of population migration between the city pairs. All cities included had no less than five cases from 15 Jan. to 18 Mar. 2020 inclusive. Wuhan was locked down at 10 am on 23 Jan., so we consider only people that traveled from Wuhan to the destination city between 17 and 23 Jan. 2020. All data were taken from the official website of Baidu Migration (https://qianxi.baidu.com/ 2020/). To better fit the model, we do not include the data of Wuhan City since its large number of the confirmed case counts skew the data and thus may reduce the robustness of the model.

Daily confirmed case counts and daily air pollutants were collected from the official website of Harvard University (https://dataverse.harvard.edu). Meteorological indexes, including average temperature (AT), diurnal temperature range (DTR), relative humidity (RH), wind velocity (WV), air pressure (AP), precipitation (PRE), and hours of sunshine (HS), were obtained from China's Meteorological Data 
Sharing Service System (http://data.cma.cn/site/index.html). Air pollutant data included particulate matter with aerodynamic diameter $\leq 2.5 \mu \mathrm{m}\left(\mathrm{PM}_{2.5}\right)$, nitrogen dioxide $\left(\mathrm{NO}_{2}\right)$, sulfur dioxide $\left(\mathrm{SO}_{2}\right)$, carbon monoxide $(\mathrm{CO})$, and ozone $\left(\mathrm{O}_{3}\right)$. Pollutant concentrations and meteorology parameters were available as daily means in each city; we calculated a single mean for the 63 days of our date range for use in the model.

\section{Statistical analysis}

Descriptive analysis was performed on all data to explore the characteristics of total confirmed case counts, average concentration of $\mathrm{O}_{3}, \mathrm{NO}_{2}, \mathrm{SO}_{2}, \mathrm{CO}, \mathrm{PM}_{2.5}$, AT, DTR, $\mathrm{RH}, \mathrm{WV}, \mathrm{AP}$, PRE, HS, and MSI. Meanwhile, to account for the lag effect and the latent period of COVID-19, we evaluated associations with confirmed case counts (dependent variable) using lags of $0,3,7$, and $14 \mathrm{~d}$ for air pollutants and meteorological factors (independent variables) (Liu et al. 2020a), i.e., we fit the model with confirmed case counts data that lags behind the pollutants' concentrations and the meteorology factors. For example, for lag 3, mean of the pollutants' concentrations and the meteorology factors values were calculated using daily means from 12 Jan. to 15 Mar., 2020, rather than from 15 Jan. to 18 Mar., 2020, during which the confirmed case counts were used. Spearman correlation analysis was employed to explore the correlation between meteorological factors and air pollutants, and among air pollutants, meteorological factors and confirmed case counts. We used generalized linear models with a negative binomial error distribution to analyze associations between air pollutant factors $\mathrm{O}_{3}, \mathrm{NO}_{2}, \mathrm{SO}_{2}, \mathrm{CO}$, and $\mathrm{PM}_{2.5}$ ), meteorological factors (AT, DTR, RH, WV, AP, PRE, and HS), MSI, and the total counts of confirmed case since the count data was expected to be clustered and thus over-dispersed. First, we established simple negative binomial regression models (including only one independent variable) to analyze each air pollutant, meteorological factor, and MSI effects on confirmed case counts. We then conducted multiple negative binomial regression models (including multiple independent variables), with and without MSI, that included all abovementioned air pollutants and meteorological factors since the independent variables are not strongly correlated (all $|r|<0.9$ ). The general negative binomial regression equation is illustrated in Eq. (1):

$\log (\lambda)=\beta 0+\beta 1 X 1+\beta 2 X 2+\ldots+\beta m X m$

In Eq. (1), where $\lambda$ represents the risk of being a confirmed case counts, $X 1, X 2, \ldots, X m$ are the factors that affect $\lambda$; and $\beta 1, \beta 2, \ldots, \beta m$ are the partial coefficients of $X 1, X 2$, and $X m$, respectively. To explore the interaction effects, we included $X i * X j$ as an interaction term in the model, where $X i$ and $X j$ represent an air pollutant or a meteorological factor. When we fitted the model each time, there was only one interaction term putting in it. A stratified analysis was done to consider the effect of air pollutants on confirmed COVID-19 cases under different levels of meteorological factors. When a significant interaction effect was present in the negative binomial model, the meteorological factor was stratified into two groups using the median as the dividing point, and a negative binomial model containing all pollutants and remaining meteorological factors was fitted to analyze the effect of air pollutants on the confirmed number of COVID-19 cases was done for each group.

All statistical analyses were performed using SPSS version 22.0 (SPSS Inc., Chicago, IL, USA) and R Core Team (2020). $\mathrm{R}$ : A language and environment for statistical computing. R Foundation for Statistical Computing, Vienna, Austria. URL http://www.R-project.org/ with a two-sided $P$ value $<0.05$ considered as statistically significant.

\section{Results}

\section{Study area}

Figure 1(a) displays the location of the 120 selected cities in mainland China and the total confirmed cases in each city collected from 15 Jan. 18 Mar. 2020. The latitude and longitude of these 120 cities range from $20^{\circ} 00^{\prime}$ to $47^{\circ} 23^{\prime} \mathrm{N}$ and from $99^{\circ} 11^{\prime}$ to $130^{\circ} 55^{\prime} \mathrm{E}$, respectively. Most cases were concentrated in the central and eastern parts of mainland China, with fewer cases in the northwest. The detailed distribution of confirmed COVID-19 cases in the 120 cities is given in Table S1. Hubei province contained the majority of confirmed COVID-19 cases, excluding Wuhan City, Xiangfan, Shiyan, Yichang, Jingzhou, Suizhou, and Xiaogan were the cities with the highest number of cases ( $>500$ per city).

\section{Description of confirmed COVID-19 cases, meteoro- logical factors, and air pollutants}

Descriptive statistics (maximum and minimum values, median, and interquartile range) for the number of confirmed cases, air pollutant measures, and the meteorological parameters of the 120 cities are presented in Table 1. Among these cities, during our study period (15 Jan. to 18 Mar., 2020), the median daily concentrations of $\mathrm{CO}, \mathrm{NO}_{2}, \mathrm{SO}_{2}, \mathrm{O}_{3}$, and $\mathrm{PM}_{2.5}$ were $0.82 \mathrm{mg} / \mathrm{m}^{3}, 20.89 \mu \mathrm{g} / \mathrm{m}^{3}, 8.23 \mu \mathrm{g} / \mathrm{m}^{3}, 56.38 \mu \mathrm{g} / \mathrm{m}^{3}$, and $43.58 \mu \mathrm{g} / \mathrm{m}^{3}$, respectively. For meteorological parameters, ranges of RH, AT, PRE, AP, HS, WV, and DTR were $35.42-85.50 \%,-12.48$ to $21.29{ }^{\circ} \mathrm{C}, 0.00-6.82 \mathrm{~mm}, 758.41-$ $1024.43 \mathrm{hPa}, 1.60-9.20 \mathrm{~h}, 1.00-5.05 \mathrm{~m} / \mathrm{s}$, and 5.13 to $18.37^{\circ} \mathrm{C}$, respectively. MSI ranged from 0.01 to 5.13 . 
(a)

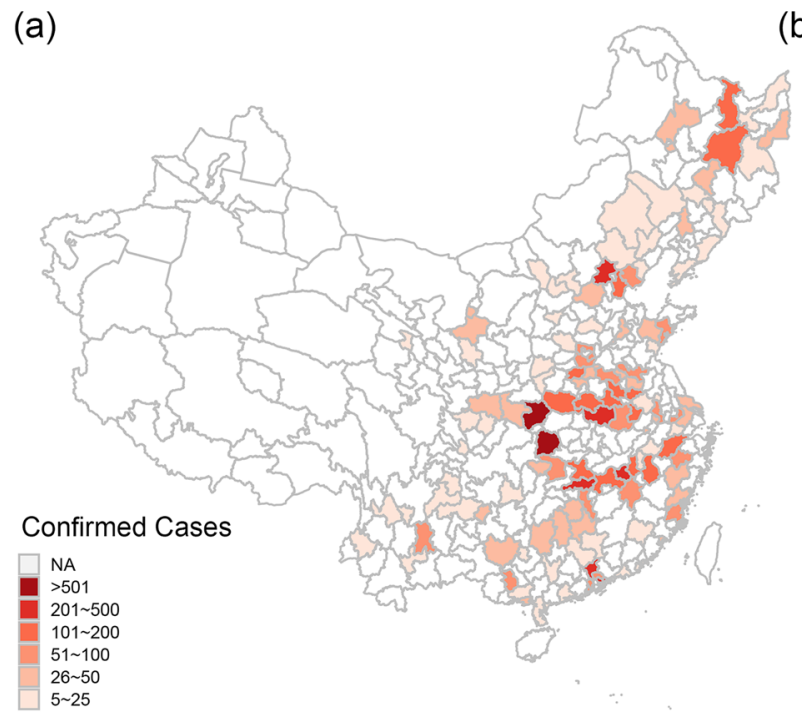

(b)

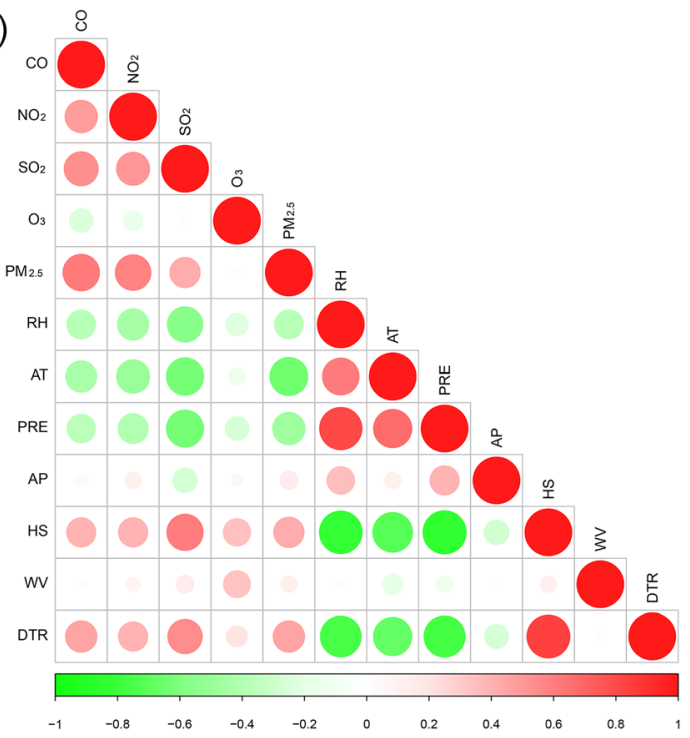

Fig. 1 Locations of 120 cities and total confirmed cases in each city on 18 Mar. 2020, and correlation analysis of meteorological factors and air pollutants. NA: Cities not included in this study

\section{Correlation analysis of air pollutants and meteorological factors}

Spearman correlation coefficients $\left(r_{s}\right)$ between concentrations of air pollutants and meteorological factors are shown in Fig. 1(b). Circle size indicates strength of relationship between two variables. All correlations are less than $|0.9|$. Therefore, all the variables could be integrated into the multiple negative binomial regression model.

Table 1 Summary of total confirmed COVID-19 cases, meteorological data, and air pollutants of 120 Chinese cities

\begin{tabular}{|c|c|c|c|c|c|}
\hline Variables & Min & $\mathrm{P} 25$ & P50 & P75 & Max \\
\hline Confirmed case counts & 5 & 14 & 36 & 81 & 3518 \\
\hline \multicolumn{6}{|c|}{ Concentrations of air pollutants } \\
\hline $\mathrm{CO}\left(\mathrm{mg} / \mathrm{m}^{3}\right)$ & 0.42 & 0.69 & 0.82 & 0.98 & 1.67 \\
\hline $\mathrm{NO}_{2}\left(\mu \mathrm{g} / \mathrm{m}^{3}\right)^{*}$ & 5.06 & 16.65 & 20.89 & 28.06 & 44.01 \\
\hline $\mathrm{SO}_{2}\left(\mu \mathrm{g} / \mathrm{m}^{3}\right)$ & 2.70 & 5.92 & 8.23 & 13.83 & 41.74 \\
\hline $\mathrm{O}_{3}\left(\mu \mathrm{g} / \mathrm{m}^{3}\right)^{*}$ & 29.63 & 48.42 & 56.38 & 62.66 & 85.94 \\
\hline $\mathrm{PM}_{2.5}\left(\mu \mathrm{g} / \mathrm{m}^{3}\right)$ & 13.62 & 30.75 & 43.58 & 59.54 & 94.83 \\
\hline \multicolumn{6}{|l|}{ Meteorological factors } \\
\hline $\mathrm{RH}(\%)$ & 35.42 & 62.43 & 73.71 & 79.28 & 85.50 \\
\hline $\mathrm{AT}\left({ }^{\circ} \mathrm{C}\right)$ & -12.48 & 2.10 & 8.14 & 10.77 & 21.29 \\
\hline PRE (mm) & 0.00 & 0.36 & 0.95 & 2.64 & 6.82 \\
\hline $\mathrm{AP}(\mathrm{hPa})$ & 758.41 & 978.83 & 1008.22 & 1016.43 & 1024.43 \\
\hline $\mathrm{HS}(\mathrm{h})$ & 1.60 & 3.31 & 4.48 & 6.91 & 9.20 \\
\hline $\mathrm{WV}(\mathrm{m} / \mathrm{s})^{*}$ & 1.00 & 1.78 & 2.19 & 2.57 & 5.05 \\
\hline DTR $\left({ }^{\circ} \mathrm{C}\right)$ & 5.13 & 6.73 & 8.92 & 10.90 & 18.37 \\
\hline MSI & 0.01 & 0.02 & 0.13 & 0.37 & 5.13 \\
\hline
\end{tabular}

* The data were normal distribution by normal distribution test

\section{Effects of air pollutants and meteorological parameters on confirmed case counts}

The relationship between pollutants, meteorological parameters, and confirmed case counts for the lag of $14 \mathrm{~d}$ are presented in a scatter plot in Fig. 2. Positive associations were present between the confirmed case counts and the pollutant measure $\mathrm{PM}_{2.5}(P=0.024)$, and the meteorological measures $\mathrm{RH}(P=$ $0.001)$, PRE $(P=0.015)$ and AP $(P<0.001)$. Negative associations occurred between the confirmed case counts and the pollutant $\mathrm{SO}_{2}(P<0.001)$ and the meteorological variable $\mathrm{HS}$ $(P=0.018)$. Correlations between confirmed case counts and all other variables were not significant.

\section{Negative binomial regression model analysis}

Simple negative binomial regression results are shown in Fig. $\mathrm{S} 1$ (a-d). $\mathrm{CO}, \mathrm{NO}_{2}, \mathrm{SO}_{2}, \mathrm{O}_{3}, \mathrm{PM}_{2.5}$, RH, AT, AP, HS, WV, and MSI were significantly associated with confirmed cases counts (all $P<0.05$ ). PRE had no effect on confirmed case counts for lags of $0,3,7$, and $14 \mathrm{~d}$, while DTR was significantly associated with confirmed cases counts at lags of 7 and $14 \mathrm{~d}$. The multiple negative binomial regression model results (without adjusting for MSI) are shown in Fig. 3(a1-d1). CO, $\mathrm{PM}_{2.5}$, and RH were positively associated with confirmed case counts, while $\mathrm{SO}_{2}$ was negatively associated with confirmed case counts at lags $0,3,7$, and $14 \mathrm{~d}$. However, $\mathrm{O}_{3}$ has a positive effect on confirmed case counts at lag 0 and WV has a positive effect on confirmed case counts at lag $14 \mathrm{~d}$. After adjusting for migration using MSI, CO, $\mathrm{PM}_{2.5}, \mathrm{RH}$, $\mathrm{O}_{3}, \mathrm{SO}_{2}$, and WV were also statistically significant, as shown in Fig. 3(a2-d2). 

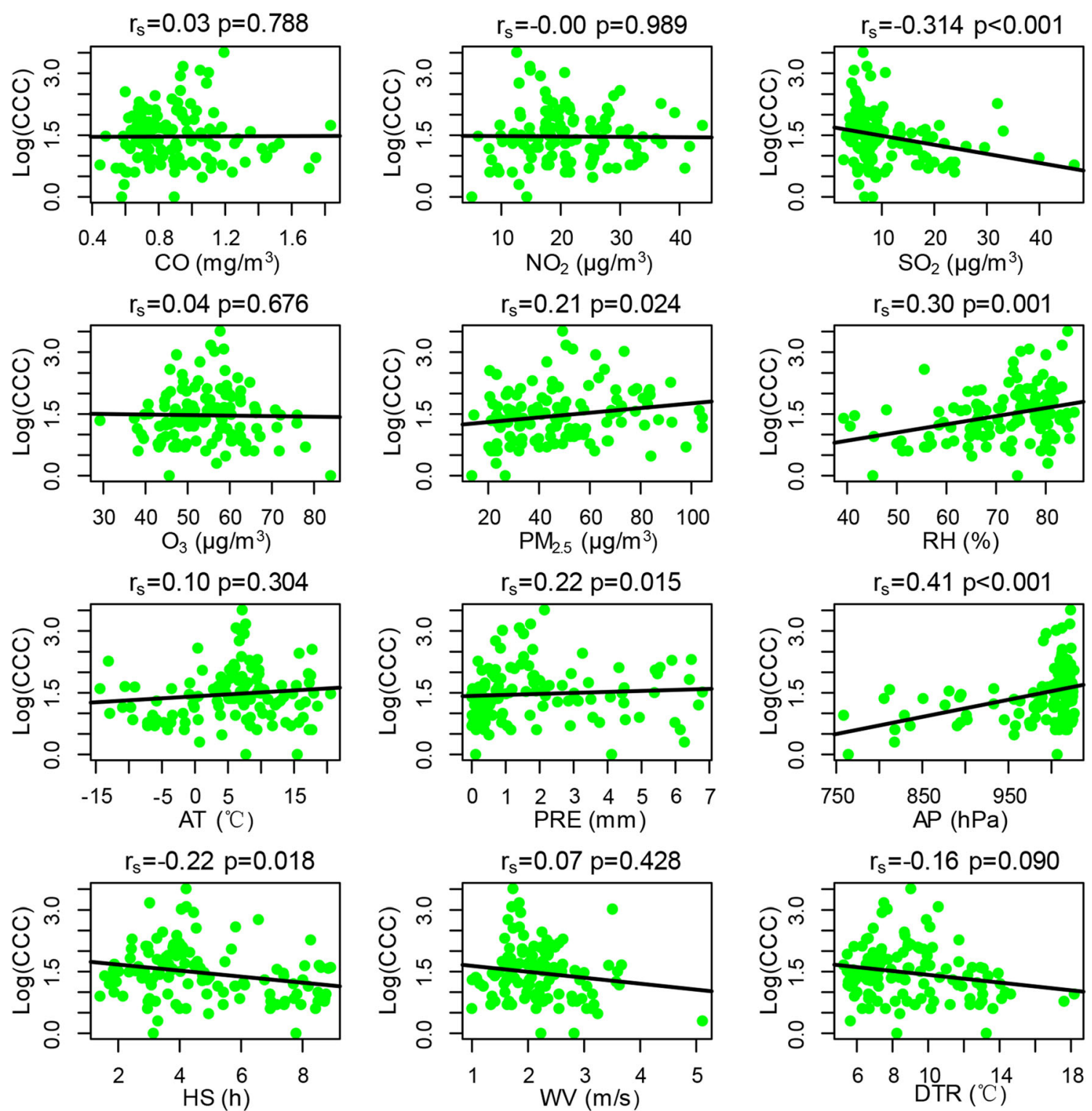

Fig. 2 Correlation analysis of confirmed case counts with air pollution and meteorological parameters. $\log (\mathrm{CCC})=\log ($ confirmed case counts)

\section{Interaction effects between air pollutants and meteorological factors on COVID-19 confirmed cases}

After testing all the interaction of ambient air pollutants and meteorological factors with totally 66 combinations in each model, 14 pairs exhibited significant interactive effects $(P<0.05)$ between the all the factors on COVID-19 confirmed cases after adjusting MSI (Table 2). It indicated that the following 6 pairs including $\mathrm{CO}$ interacted with $\mathrm{RH}$ and $\mathrm{O}_{3}$, $\mathrm{PM}_{2.5}$ interacted with PRE, $\mathrm{SO}_{2}$ interacted with $\mathrm{O}_{3}, \mathrm{HS}$ interacted with PRE, and WV interacted with RH showed significantly positive effects on the COVID-19 confirmed cases. While the rest of the 8 pairs of $\mathrm{CO}-\mathrm{HS} / \mathrm{DTR} / \mathrm{NO}_{2}$, $\mathrm{SO}_{2}, \mathrm{PM}_{2.5} \mathrm{CO} / \mathrm{NO}_{2}, \mathrm{SO}_{2}-\mathrm{AP}$, and DTR-RH were displayed significantly negative effects on the COVID-19 confirmed cases.
Stratified analysis of ambient air pollutants and/or meteorological factors interaction effects on COVID-19 confirmed cases were listed in Table 3. Three variable groups included air pollutants stratified in meteorological factors, air pollutants stratified in other air pollutants and meteorological factors stratified in other meteorological factors.

The adjusted air pollutants, meteorological factors and MSI, and under the levels of HS values below 50th percentile and $\mathrm{HS}$ and above 50th percentile had no significant effects on COVID-19 case counts by CO. At the low DTR level $(<50$ th percentile), an increase of $\mathrm{CO}$ by $1 \mathrm{mg} / \mathrm{m}^{3}$ is expected to increase the log of risk of being confirmed COVID-19 cases by a factor of $>5(\beta=5.763, P=0.001)$, while the same increase in $\mathrm{CO}$ at the high DTR level ( $\geq 50$ th percentile) increases the risk by a factor of $<1(\beta=0.931, P=0.035)$. $\mathrm{CO}$ has no significant effect on confirmed case counts at low RH 
(a1) Variables

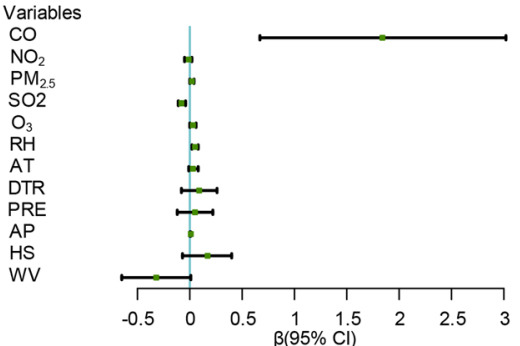

(b1) Variables

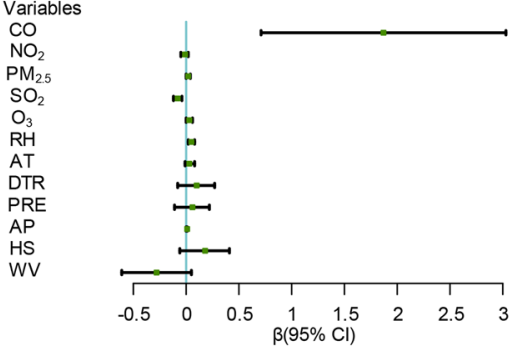

(c1) Variables



(d1) Variables

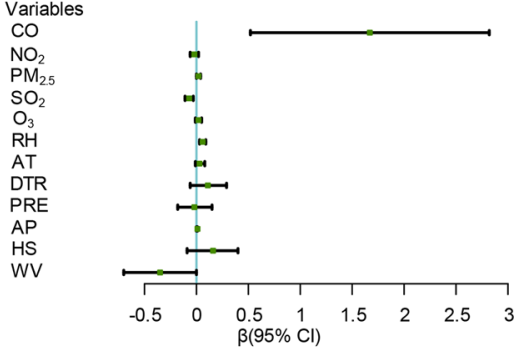

$\beta(95 \% \mathrm{Cl})$
$1.84(0.67 \sim 3.02)$ $\begin{array}{cc}1.04(0.67 \sim 3.02) & 0.002 \\ -0.01(-0.05 \sim 0.02) & 0.387\end{array}$ $0.02(0.00 \sim 0.04) \quad 0.030$ $-0.08(-0.11 \sim-0.04)<0.001$ $0.03(0.00 \sim 0.06) \quad 0.045$ $0.05(0.02 \sim 0.08) \quad 0.001$ $0.03(-0.01 \sim 0.08) \quad 0.160$ $0.09(-0.08 \sim 0.26) \quad 0.316$ $0.05(-0.12 \sim 0.22) \quad 0.564$ $0.01(0.00 \sim 0.01) \quad 0.006$ $\begin{array}{ll}0.17(-0.07 \sim 0.40) & 0.159 \\ -0.32(-0.65 \sim 0.01) & 0.055\end{array}$

$\beta(95 \% \mathrm{Cl})$ 1.87(0.71 3.03) $\quad 0.002$ $\begin{array}{ll}1.01(-0.05 \sim 0.02) & 0.402\end{array}$ $0.02(0.00 \sim 0.04) \quad 0.045$ $0.08(-0.12 \sim-0.04) \quad<0.001$ $0.03(0.00 \sim 0.06) \quad 0.060$ $0.05(0.02 \sim 0.08) \quad 0.001$ $0.03(-0.01 \sim 0.08) \quad 0.153$ $0.10(-0.08 \sim 0.27) \quad 0.278$ $0.06(-0.11 \sim 0.22) \quad 0.522$ $0.01(0.00 \sim 0.01) \quad 0.005$ $0.18(-0.06 \sim 0.41) \quad 0.134$ $\begin{array}{ll}0.18(-0.06 \sim 0.41) & 0.134 \\ -0.28(-0.61 \sim 0.05) & 0.097\end{array}$
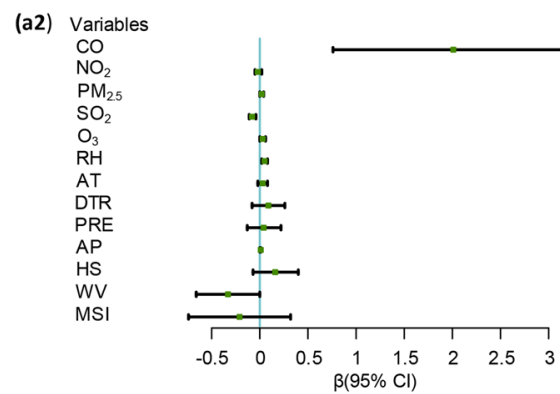

(b2) Variables
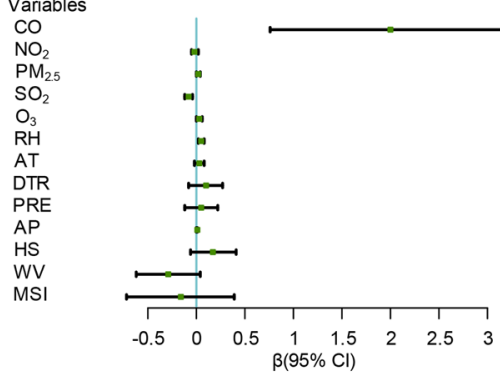

(c2) Variables Variables
$\mathrm{CO}$
$\mathrm{NO}_{2}$
$\mathrm{PM}_{25}$
$\mathrm{SO}_{2}$
$\mathrm{O}_{3}$
$\mathrm{RH}$
$\mathrm{AT}$
$\mathrm{DTR}$
$\mathrm{PRE}$
$\mathrm{AP}$
$\mathrm{HS}$
WV
$\mathrm{MSI}$

$\beta(95 \% \mathrm{Cl})$
$1.82(0.68 \sim 2 \%)$ 1.82(0.68 2.96) 0.002 $\begin{array}{ll}-0.02(-0.05 \sim 0.02) & 0.393\end{array}$ $0.02(0.00 \sim 0.04) \quad 0.044$ $\begin{array}{ll}0.03(0.00 \sim 0.06) & 0.073\end{array}$ $0.05(0.02 \sim 0.08) \quad<0.001$ $\begin{array}{ll}0.04(-0.01 \sim 0.08) & 0.145\end{array}$ $\begin{array}{ll}0.04(-0.01 \sim 0.08) & 0.145 \\ 0.10(-0.08 \sim 0.27) & 0.278\end{array}$ $0.07(-0.10 \sim 0.23) \quad 0.434$ $\begin{array}{ll}0.01(0.00 \sim 0.01) & 0.009\end{array}$ $0.18(-0.05 \sim 0.42) \quad 0.132$ $\begin{array}{ll}-0.30(-0.64 \sim 0.03) & 0.076\end{array}$ $\begin{array}{cc}\beta(95 \% \mathrm{Cl}) & \mathrm{P} \\ 1.67(0.52 \sim 2.82) & 0.005\end{array}$ $\begin{array}{ll}-0.02(-0.06 \sim 0.02) & 0.320\end{array}$ $\begin{array}{cc}0.02(0.00 \sim 0.04) & 0.049 \\ -0.07(-0.11 \sim-0.03) & <0.001\end{array}$ $\begin{array}{cc}0.07(-0.11 \sim-0.03) & <0.001 \\ 0.02(-0.01 \sim 0.05) & 0.180\end{array}$ $\begin{array}{cc}0.02(-0.01 \sim 0.05) & 0.180 \\ 0.06(0.03 \sim 0.09) & <0.001\end{array}$ $\begin{array}{ll}0.06(0.03 \sim 0.09) & <0.001 \\ 0.03(-0.01 \sim 0.08) & 0.162\end{array}$ $\begin{array}{ll}0.03(-0.01 \sim 0.08) & 0.162 \\ 0.11(-0.06 \sim 0.29) & 0.207\end{array}$ $\begin{array}{ll}0.11(-0.06 \sim 0.29) & 0.207 \\ -0.02(-0.18 \sim 0.15) & 0.841\end{array}$ $\begin{array}{ll}0.02(-0.18 \sim 0.15) & 0.841 \\ 0.01(0.00 \sim 0.01) & 0.002\end{array}$ $\begin{array}{ll}0.01(0.00 \sim 0.01) & 0.002 \\ 0.16(-0.09 \sim 0.40) & 0.215\end{array}$ $\begin{array}{ll}0.16(-0.09 \sim 0.40) & 0.215 \\ -0.35(-0.70 \sim 0.00) & 0.047\end{array}$

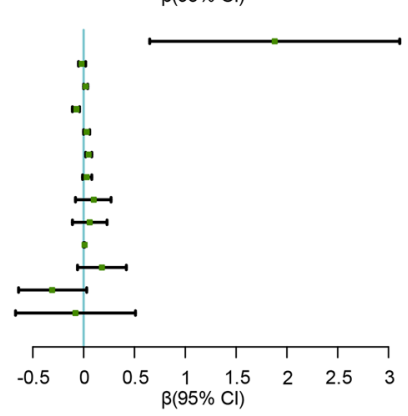

$\beta(95 \% \mathrm{Cl}) \quad \mathrm{P}$ $\begin{array}{ll}2.01(0.76 \sim 3.25) & 0.002\end{array}$ $0.02(0.00 \sim 0.04) \quad 0.040$ $-0.08(-0.11 \sim-0.04)<0.001$ $0.03(0.00 \sim 0.06)$ $0.05(0.02 \sim 0.08) \quad 0.041$ $0.03(-0.02 \sim 0.08) \quad 0.191$

$0.09(-0.08 \sim 0.26) \quad 0.191$

$0.04(-0.13 \sim 0.22) \quad 0.295$

$0.04(-0.13 \sim 0.22)-0.649$

$0.16(-0.07 \sim 0.40) \quad 0.179$

$\begin{array}{ll}-0.33(-0.66 \sim 0.00) \quad 0.048 & 0.07 \%\end{array}$

$\begin{array}{ll}-0.21(-0.74 \sim 0.32) & 0.437\end{array}$

$\beta(95 \% \mathrm{Cl}) \quad P$ $\begin{array}{ll}2.00(0.76 \sim 3.24) & 0.002\end{array}$ $\begin{array}{ll}2.00(0.76 \sim 3.05 \sim 0.02) & 0.341 \\ 0.02(0.00 \sim 0.04) & 0.057\end{array}$ $-0.08(-0.12 \sim-0.04) \quad<0.00$

$0.03(0.00 \sim 0.06)<0.001$

$0.05(0.00 \sim 0.06) \quad 0.059$

$0.05(0.02 \sim 0.08) \quad 0.001$

$0.03(-0.02 \sim 0.08) \quad 0.180$

$0.10(-0.08 \sim 0.27) \quad 0.265$

$\begin{array}{ll}0.05(-0.12 \sim 0.22) & 0.591 \\ 0.01(0.00 \sim 0.01) & 0.005\end{array}$

$\begin{array}{ll}0.01(0.00 \sim 0.01) & 0.005 \\ 0.17(-0.06 \sim 0.41) & 0.151\end{array}$

$\begin{array}{cc}0.17(-0.06 \sim 0.41) & 0.151 \\ -0.29(-0.62 \sim 0.04) & 0.088\end{array}$

$\begin{array}{ll}-0.29(-0.62 \sim 0.04) & 0.088 \\ -0.16(-0.72 \sim 0.39) & 0.569\end{array}$

$\beta(95 \% \mathrm{Cl}) \quad P$

1.88(0.65 3.11) 0.003 $\begin{array}{cc}-0.02(-0.05 \sim 0.02) & 0.372 \\ 0.02(0.00 \sim 0.04) & 0.051\end{array}$ $0.02(0.00 \sim 0.04) \quad 0.051$ $\begin{array}{cc}-0.07(-0.11 \sim-0.04) & <0.001\end{array}$ $0.03(0.00 \sim 0.06) \quad 0.072$ $0.05(0.02 \sim 0.08)<0.001$ $0.03(-0.01 \sim 0.08) \quad 0.159$ $0.10(-0.08 \sim 0.27) \quad 0.271$ $0.06(-0.11 \sim 0.23) \quad 0.466$ $0.01(0.00 \sim 0.01) \quad 0.009$ $0.18(-0.06 \sim 0.42) \quad 0.143$ $-0.31(-0.64 \sim 0.03) \quad 0.073$ $\begin{array}{ll}-0.08(-0.67 \sim 0.51) & 0.790\end{array}$

(d2) Variables

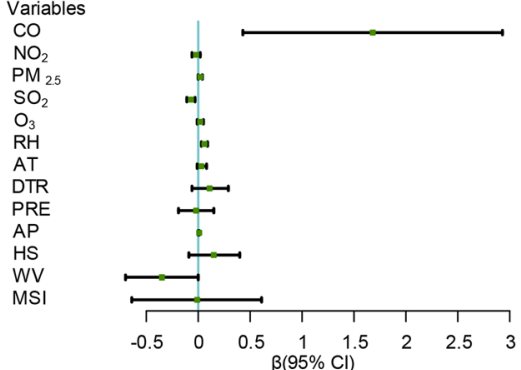

$\beta(95 \% \mathrm{Cl}) \quad P$ 1.68(0.43 2.93) 0.008 $0.02(-0.06 \sim 0.02) \quad 0.333$ $\begin{array}{ll}0.02(0.00 \sim 0.04) & 0.052 \\ 0.07(-0.11 \sim-0.03) & <0.001\end{array}$ $\begin{array}{ll}-0.07(-0.11 \sim-0.03) & <0.001 \\ 0.02(-0.01 \sim 0.05) & 0.180\end{array}$ $\begin{array}{ll}0.02(-0.01 \sim 0.05) & 0.180 \\ 0.06(0.03 \sim 0.09) & <0.001\end{array}$ $0.03(-0.01 \sim 0.08) \quad 0.167$ $0.11(-0.06 \sim 0.29) \quad 0.209$ $0.02(-0.19 \sim 0.15) \quad 0.837$ $0.01(0.00 \sim 0.01) \quad 0.002$ $0.15(-0.09 \sim 0.4) \quad 0.223$ $-0.35(-0.70 \sim 0.00) \quad 0.048$ $-0.01(-0.64 \sim 0.61) \quad 0.964$

Fig. 3 The relationship between air pollutants, meteorological factors, and confirmed case counts in a multiple negative binomial regression model with and without adjusting for migrations with MSI

level, but at a high RH level, a $1-\mathrm{mg} / \mathrm{m}^{3}$ increase of CO significantly raises the risk of being confirmed case $(\beta=6.045$, $P<0.001)$. Besides, $\mathrm{CO}$ significantly associated with confirmed case counts at low level of $\mathrm{NO}_{2}(\beta=5.024$, $P<0.001), \mathrm{SO}_{2}(\beta=7.081, P<0.001)$, and at level high level of $\mathrm{O}_{3}(\beta=4.074, P<0.001)$. Increase of $\mathrm{SO}_{2}$ was associated with lower risk of confirmed case counts $(\beta=-0.243$, $P<0.001)$ at high level of AP; and an increase of $\mathrm{SO}_{2}$ was associated with lower risk of confirmed case counts $(\beta=$ $-0.129, P=0.001)$ at low level of $\mathrm{O}_{3} . \mathrm{PM}_{2.5}$ variation had no significant effect on COVID-19 case counts by either low or high $\mathrm{PRE} / \mathrm{CO} / \mathrm{NO}_{2}$ levels. WV was significantly associated with high level of RH $(\beta=-0.506, P=0.006)$. These results indicate that the effects of one of the air pollutants and meteorological factors vary depending on the level of another air pollutants and meteorological factors. It can be concluded that the interaction of the air pollutants and/or meteorological affects the COVID-19 confirmed cases counts.

\section{Discussion}

In this work, we explored the role of air pollutants, meteorological factors, and their interactive effects on confirmed case counts in 120 Chinese cities. We focused on these cities as their meteorological data was available (this is not true for all cities in China). Our results indicate that air pollutants, meteorological factors, and their interaction are associated with 
Table 2 The significant interaction effects of the ambient air pollutants and/or meteorological factors on COVID-19 confirmed cases after adjusting MSI $(P<0.05)$

\begin{tabular}{llllll}
\hline Variable & Interactant & $\beta$ & Lower 95\% CI & Upper 95\% CI & $P$ \\
\hline $\mathrm{CO}$ & $\mathrm{HS}$ & -0.811 & -1.420 & -0.202 & 0.009 \\
& $\mathrm{DTR}$ & -0.365 & -0.693 & -0.037 & 0.029 \\
& $\mathrm{RH}$ & 0.137 & 0.058 & 0.216 & 0.001 \\
& $\mathrm{NO}_{2}$ & -0.202 & -0.291 & -0.113 & $<0.001$ \\
& $\mathrm{SO}_{2}$ & -0.167 & -0.286 & -0.048 & 0.006 \\
& $\mathrm{O}_{3}$ & 0.183 & 0.092 & 0.274 & $<0.001$ \\
$\mathrm{PM}_{2.5}$ & $\mathrm{PRE}$ & 0.022 & 0.008 & 0.036 & 0.002 \\
& $\mathrm{CO}$ & -0.070 & -0.118 & -0.022 & 0.004 \\
& $\mathrm{NO}$ & -0.002 & -0.004 & -0.001 & $<0.001$ \\
$\mathrm{SO}_{2}$ & $\mathrm{AP}$ & -0.001 & -0.001 & 0.000 & 0.014 \\
& $\mathrm{O}_{3}$ & 0.005 & 0.001 & 0.008 & 0.011 \\
$\mathrm{HS}$ & $\mathrm{PRE}$ & 0.185 & 0.049 & 0.320 & 0.008 \\
$\mathrm{WV}^{2}$ & $\mathrm{RH}$ & 0.030 & 0.005 & 0.056 & 0.021 \\
$\mathrm{DTR}$ & $\mathrm{RH}$ & -0.015 & -0.025 & -0.004 & 0.005 \\
\hline
\end{tabular}

COVID-19 confirmed case counts, with and without adjusting using MSI.

Previous studies indicate that meteorological factors and air pollutants influence prevalence of infectious diseases (e.g., influenza, SARS, MERS, COVID-19 (Cai et al. 2007, Liu et al. 2020a, Prata et al. 2020, Tan et al. 2005, van Doremalen et al. 2013, Yusuf et al. 2007)). An ecological analysis carried out in China demonstrated that air pollutants increase SARS case fatalities (Cui et al. 2003). As a major component of air pollution, particulate matter is associated with a variety of cardiorespiratory diseases, including acute lower respiratory tract infections. $\mathrm{PM}_{2.5}$ has adverse effects on human health and is associated with many diseases like myocardial infarction (Chen et al. 2020) and hypertension (Yang et al. 2018), especially respiratory disease (Horne et al. 2018). $\mathrm{PM}_{2.5}$ may damage bronchial immunity and epithelial cell integrity (Jiang et al. 2020), which, in turn, will reduce the body's ability to fight off viruses, making affected individuals more vulnerable to respiratory disease. Exposure to higher concentrations of $\mathrm{PM}_{2.5}$ results in greater use of healthcare resources for acute lower respiratory infection (Horne et al. 2018). Jiang et al. (Jiang et al. 2020), Suhaimi et al. (Suhaimi et al. 2020) and Zhu et al. (Zhu et al. 2020) studies suggested that $\mathrm{PM}_{2.5}$ was positively associated with confirmed COVID19 cases, which were consistent with our results (Fig. 3). Cai et al. (2007) indicated that no correlation exists between air pollution (including particulate matter, $\mathrm{SO}_{2}, \mathrm{NO}_{2}, \mathrm{O}_{3}$, and CO) and SARS outbreaks (Cai et al. 2007). However, our results are consistent with Zhu et al. (Zhu et al. 2020), who found that increases in $\mathrm{CO}$ were positively associated with the number of confirmed COVID-19 cases, while $\mathrm{SO}_{2}$ was negatively correlated with COVID-19 cases (Fig. 3). The difference is that migration was taken into account in our analysis and it was not in the analysis by Zhu et al. (Zhu et al. 2020). Hu's (Hu Jianxiong et al. 2020) study indicated that the cumulative number of reported COVID-19 cases in each province was positively correlated with the population index of Wuhan moving out to each province, and the correlation coefficient is 0.84 , so we believe that it is necessary to control the population migration.

Kesic et al. suggests that exposure to $\mathrm{O}_{3}$ might disrupt the protease/anti-protease balance of human airways, contributing to an increased influenza A infection rate (Kesic et al. 2012). We similarly found that exposure to $\mathrm{PM}_{2.5}, \mathrm{CO}$ and $\mathrm{O}_{3}$ increased likelihood of being infected by COVID-19 (Fig. 3). Understanding the relationship between air pollutant exposure and health provides clues regarding effective protective measures that can reduce the incidence or risk of diseases. Despite the positive relationship between air pollutants (including $\mathrm{PM}_{2.5}, \mathrm{CO}$, and $\mathrm{O}_{3}$ ) and confirmed COVID-19 cases and the negative relationship between $\mathrm{SO}_{2}$ and confirmed COVID-19 cases that we found, the mechanism by which pollutants affect COVID-19, whether via changes in the transmission of the virus or in the immunity of the human body, remains unknown. Further experimental studies are required to explore the molecular regulation mechanisms involved.

Meteorological factors such as AT, DTR, RH, WV, AP, PRE, and HS are important factors influencing the survival of microorganisms in the external environment (Anwar et al. 2019, Bezirtzoglou et al. 2011, Casadevall 2020, Chan et al. 2011, Liu et al. 2020a). For decades, experts have issued warnings that climate change may affect the epidemiology of infectious diseases (Casadevall 2020). Global warming, rising sea levels, and climate change will be accompanied by new and unknown diseases (Bezirtzoglou et al. 2011, Casadevall 2020). Meteorological factors may change the host's behavior, e.g., by affecting time spent indoors or outdoors, affect the host's defense mechanisms (inhalation of dry and cold air will cause damage to the cleaning function of cilia), or change the infectivity and stability of the virus. Although many studies on meteorological factors and respiratory infectious diseases (including COVID-19) exist, research results remain controversial. While temperature is unlikely to act alone in determining the population's health, but it can work synergistically with other weather parameters to do so (Huang et al. 2017).

COVID-19 case numbers appear to increase with increasing temperature in the range of -20 to $20^{\circ} \mathrm{C}$ (Liu et al. 2020a). Other studies have reported that when AT is below $3{ }^{\circ} \mathrm{C}$, it is positively correlated with confirmed COVID-19 case counts (Xie and Zhu, 2020). A Brazilian study suggests a negative linear relationship exists between AT and daily cumulative confirmed cases of COVID-19 in the temperature range of 16.8 to $27.4{ }^{\circ} \mathrm{C}$ (Prata et al. 2020), while Auler et al.'s research 
Table 3 Stratified analysis of ambient air pollutants and/or meteorological factors' interaction effects on COVID-19 confirmed cases

\begin{tabular}{|c|c|c|c|c|c|c|}
\hline Variable group & Variable & Stratified factor & $\beta$ & Lower 95\% CI & Upper $95 \%$ CI & $P$ \\
\hline \multirow{10}{*}{$\begin{array}{l}\text { Effect of air pollutants } \\
\text { stratified in } \\
\text { meteorological factors }\end{array}$} & \multirow[t]{2}{*}{$\mathrm{CO}$} & $\mathrm{HS}<\mathrm{P} 50$ & 3.321 & -0.230 & 6.873 & 0.067 \\
\hline & & $\mathrm{HS} \geq \mathrm{P} 50$ & 1.115 & -0.247 & 2.478 & 0.108 \\
\hline & \multirow[t]{2}{*}{$\mathrm{CO}$} & DTR $<$ P50 & 5.763 & 2.402 & 9.124 & 0.001 \\
\hline & & $\mathrm{DTR} \geq \mathrm{P} 50$ & 0.931 & 0.066 & 1.796 & 0.035 \\
\hline & \multirow[t]{2}{*}{$\mathrm{CO}$} & $\mathrm{RH}<\mathrm{P} 50$ & 0.930 & -0.574 & 2.434 & 0.226 \\
\hline & & $\mathrm{RH} \geq \mathrm{P} 50$ & 6.045 & 3.247 & 8.844 & $<0.001$ \\
\hline & \multirow[t]{2}{*}{$\mathrm{SO}_{2}$} & $\mathrm{AP}<\mathrm{P} 50$ & -0.006 & -0.052 & 0.041 & 0.812 \\
\hline & & $\mathrm{AP} \geq \mathrm{P} 50$ & -0.243 & -0.307 & -0.178 & $<0.001$ \\
\hline & \multirow[t]{2}{*}{$\mathrm{PM}_{2.5}$} & $\mathrm{PRE}<\mathrm{P} 50$ & 0.004 & -0.019 & 0.027 & 0.727 \\
\hline & & $\mathrm{PRE} \geq \mathrm{P} 50$ & 0.049 & -0.009 & 0.107 & 0.100 \\
\hline \multirow{12}{*}{$\begin{array}{l}\text { Effect of air pollutants } \\
\text { stratified in other air pollutants }\end{array}$} & \multirow[t]{2}{*}{$\mathrm{PM}_{2.5}$} & $\mathrm{CO}<\mathrm{P} 50$ & 0.003 & -0.012 & 0.019 & 0.665 \\
\hline & & $\mathrm{CO} \geq \mathrm{P} 50$ & 0.018 & -0.035 & 0.071 & 0.504 \\
\hline & \multirow[t]{2}{*}{$\mathrm{PM}_{2.5}$} & $\mathrm{NO}_{2}<\mathrm{P} 50$ & 0.021 & -0.007 & 0.050 & 0.142 \\
\hline & & $\mathrm{NO}_{2} \geq \mathrm{P} 50$ & 0.005 & -0.016 & 0.026 & 0.633 \\
\hline & \multirow[t]{2}{*}{$\mathrm{CO}$} & $\mathrm{NO}_{2}<\mathrm{P} 50$ & 5.024 & 3.087 & 6.962 & $<0.001$ \\
\hline & & $\mathrm{NO}_{2} \geq \mathrm{P} 50$ & -0.987 & -2.323 & 0.349 & 0.148 \\
\hline & \multirow[t]{2}{*}{$\mathrm{CO}$} & $\mathrm{SO}_{2}<\mathrm{P} 50$ & 7.081 & 3.923 & 10.239 & $<0.001$ \\
\hline & & $\mathrm{SO}_{2} \geq \mathrm{P} 50$ & 0.237 & -1.130 & 1.604 & 0.734 \\
\hline & \multirow[t]{2}{*}{$\mathrm{CO}$} & $\mathrm{O}_{3}<\mathrm{P} 50$ & -0.306 & -1.460 & 0.848 & 0.603 \\
\hline & & $\mathrm{O}_{3} \geq \mathrm{P} 50$ & 4.074 & 2.301 & 5.847 & $<0.001$ \\
\hline & \multirow[t]{2}{*}{$\mathrm{SO}_{2}$} & $\mathrm{O}_{3}<\mathrm{P} 50$ & -0.129 & -0.207 & -0.052 & 0.001 \\
\hline & & $\mathrm{O}_{3} \geq \mathrm{P} 50$ & -0.036 & -0.094 & 0.022 & 0.224 \\
\hline \multirow{6}{*}{$\begin{array}{l}\text { Effect of meteorological } \\
\text { factors stratified in other } \\
\text { meteorological factors }\end{array}$} & \multirow[t]{2}{*}{ HS } & $\mathrm{PRE}<\mathrm{P} 50$ & 0.183 & -0.032 & 0.399 & 0.095 \\
\hline & & $\mathrm{PRE} \geq \mathrm{P} 50$ & 0.507 & -0.218 & 1.231 & 0.170 \\
\hline & \multirow[t]{2}{*}{ WV } & $\mathrm{RH}<\mathrm{P} 50$ & 0.013 & -0.679 & 0.705 & 0.970 \\
\hline & & $\mathrm{RH} \geq \mathrm{P} 50$ & -0.506 & -0.866 & -0.147 & 0.006 \\
\hline & \multirow[t]{2}{*}{ DTR } & $\mathrm{RH}<\mathrm{P} 50$ & 0.065 & -0.141 & 0.272 & 0.535 \\
\hline & & $\mathrm{RH} \geq \mathrm{P} 50$ & 0.052 & -0.265 & 0.369 & 0.749 \\
\hline
\end{tabular}

(also conducted in Brazilian) suggests both higher AT and RH favor COVID-19 transmission (Auler et al. 2020). The results of studies in some tropical countries emphasize that COVID19 cases positively correlate with AT (Pani et al. 2020, Suhaimi et al. 2020, Tosepu et al. 2020). Another study demonstrated that in DTR increased in range of from 5 to $15^{\circ} \mathrm{C}$, the counts of confirmed COVID-19 cases decreased, and that a non-linear relationship occurred between COVID-19 cases and absolute humidity (Liu et al. 2020a). A study of 244 cities in China found no significant associations between RH, AT and cumulative incidence rate or $\mathrm{R}_{0}$ of COVID-19 (Yao et al. 2020), which is in contrast to our finding that RH and AT are positively associated with COVID-19 case counts (Fig. 3 and $\mathrm{S} 1$, respectively). Temperature in our study ranged from -12.48 to $21.29^{\circ} \mathrm{C}$, and our results of AT as positively associated with confirmed case counts is consistent with other studies in tropical countries and China indicating that COVID-19 can survive at higher temperatures, this reveals that COVID-19 can survival under higher temperatures. Experimental research on SARS-CoV-2 confirmed that this virus is very stable at $4{ }^{\circ} \mathrm{C}$, but when the temperature increases to $70^{\circ} \mathrm{C}$, inactivation time for the virus is shortened to $5 \mathrm{~min}$ (Chin et al. 2020).

$\mathrm{Hu}$ et al. reported that low WV might increase the risk of mumps (Hu et al. 2018). Our multiple negative binomial regression models [lag $14 \mathrm{~d}$ in Fig. 3(d1)] suggest that WV is negatively associated with COVID-19 confirmed case counts, consistent with $\mathrm{Hu}$ et al. (Hu et al. 2018). Wind can affect the duration of droplets suspended in air. In indoor environments, high wind speed means that rooms are well-ventilated and in outdoor environments, high wind speed enhances dilution and removal of droplets, both of which could shorten droplet suspension time in the air (Cai et al. 2007).

Regarding rainfall, our study showed PRE is positively related to confirmed case counts (Fig. 2); however, this effect was not statistically significant in simple and multiple 
negative binomial regression analysis (Fig. S1 and 3). Some epidemiological data generally support a relationship between influenza virus infection and PRE (Pica and Bouvier, 2012). Agrawal et al. found a significant association between rainfall and influenza virus infection in India, and fewer reports of infection in the dry season (Agrawal et al. 2009). The association between PRE and respiratory syncytial virus infection showed similar results in our research and in other studies (Shek and Lee, 2003).

It demonstrated that exposure to air pollutants may damage the respiratory immune system on account of the free radicals induced by oxidative stress, which at last, would reduce the airway resistance to viral infections (Ciencewicki and Jaspers, 2007). It has been reported that air pollutants might increase the risk of COVID-19 (Coccia 2020, Martelletti and Martelletti, 2020, Zhao et al. 2014). To the best of our knowledge, interactive effects of air pollutants and meteorological factors have not previously been identified as affecting COVID-19 cases but they have been identified in the noninfectious diseases (Guo et al. 2019, Huang et al. 2017, McCormack et al. 2016) and cause-specific diseases (Chen et al. 2019). We also notice a report about the significant interaction effect between $\mathrm{PM}_{10}$ and the mean temperature on influenza (Xu et al. 2013b). Since $\mathrm{PM}_{2.5}$ is more harmful to human health and has a longer residence time, we select $\mathrm{PM}_{2.5}$ rather than $\mathrm{PM}_{10}$. In addition, we observed that under specific meteorological conditions (DTR $<\mathrm{P} 50, \mathrm{RH} \geq \mathrm{P} 50$ ) or specific pollution conditions $\left(\mathrm{NO}_{2}<\mathrm{P} 50, \mathrm{SO}_{2}<\mathrm{P} 50, \mathrm{O}_{3} \geq\right.$ $\mathrm{P} 50$ ), an increase of $\mathrm{CO}$ by $1 \mathrm{mg} / \mathrm{m}^{3}$ would raise the risk of confirmation of COVID-19 case higher than that in opposite specific meteorological or environmental pollution conditions (Table 3). For example, the effect of $\mathrm{CO}$ on confirmed cases is 5.763 at low DTR level ( $<50$ th percentile), while the effect of $\mathrm{CO}$ on confirmed cases is 0.931 in low DTR level (Table 3); this indicates that the interactive effect of CO and DTR is an antagonistic. Although the interactive effect of $\mathrm{CO}$ and $\mathrm{HS}$ was statistically significant $(\beta=-0.811, P=0.009$, Table 2$)$, the stratified analysis has not revealed differences between the two categories of HS (Table 3), and thus the biological meaning of the interaction is unclear. The interactive effects of $\mathrm{PM}_{2.5}$ with PRE, $\mathrm{CO}$ or $\mathrm{NO}_{2}$, HS with PRE, and DTR with $\mathrm{RH}$, were similar to CO-HS interaction (Table 3). We also found both of the interactive effects and stratified effect differences of $\mathrm{SO}_{2}-\mathrm{AP} / \mathrm{O}_{3}$ and WV-RH were statistically significant. Our findings suggest that the environmental pollutants and/or meteorological variables are not only influence COVID-19 spread alone, but also play important roles in combination with each other. And we partially testify a hypothesis proposed by a recent study that the air pollutants in specific meteorological conditions might promote a longer permanence of the viral particles in the air and then increase the risk of infection (Frontera et al. 2020). The pollution-to human transmission theory (Coccia 2020) could partially explain these interactive effects, but the exact mechanisms behind them require further study.

We have comprehensively evaluated the effect of environmental pollution, meteorological factors, and their interaction on the number of confirmed COVID-19 cases with and without controlling for MSI, to increase understanding of these risk factors on the transmission of COVID-19. The limitation of our research is that we only analyzed data from 120 cities in China. Further studies are required in more countries and regions to clarify the effect of environmental air pollutants on COVID-19 infection rates worldwide.

\section{Conclusion}

Our work verifies that air pollutants, meteorological factors, and their interaction affect the number of confirmed cases of COVID19 even after controlling for migration. Our study suggests that increased $\mathrm{RH}, \mathrm{CO}$, and $\mathrm{PM}_{2.5}$ concentrations are associated with increased numbers of confirmed COVID-19 cases. In addition, pollutant-meteorological factor interaction effects influenced COVID-19 infection levels. Our research provides a theoretical basis for formulating public health policies for the prevention and control of COVID-19 that take into consideration the effects and relationship of air pollutants and meteorological factors.

Supplementary Information The online version contains supplementary material available at https://doi.org/10.1007/s11356-021-12648-9.

Acknowledgements We thank Harvard University, China Meteorological Administration, and Baidu migration for providing us data.

Author contribution Jianli Zhou: conceptualization, methodology, data curation, writing-original draft preparation. Linyuan Qin: methodology, visualization, investigation, writing-original draft preparation. Xiaojing Meng: writing-reviewing and editing. Nan Liu: supervision, validation, writing-reviewing, and editing.

Funding This work was supported by National Natural Science Foundation of China (Nos. 81872584 and 81273078), National 863 Young Scientist Program (No. 2015AA020940), Science and Technology Program of Guangzhou (No. 201704020056), Scientific Research Project for University of Education Bureau of Guangzhou (No. 201831841), and Interdisciplinary Research for First-class Discipline Construction Project of Henan University (No. 2019YLXKJC04).

Data availability The datasets generated or analyzed during the current study are available on the website https://qianxi.baidu.com/2020/; for migration data; https://dataverse.harvard.edu; for COVID-19 data and air pollutants data; http://data.cma.cn/site/index.html, for meteorological data.

\section{Declarations}

Ethics approval and consent to participate Not applicable. 
Consent for publication Not applicable

Conflict of interest The authors declare that they have no conflict of interest.

\section{References}

Agrawal AS, Sarkar M, Chakrabarti S, Rajendran K, Kaur H, Mishra AC, Chatterjee MK, Naik TN, Chadha MS, Chawla-Sarkar M (2009) Comparative evaluation of real-time PCR and conventional RTPCR during a 2 year surveillance for influenza and respiratory syncytial virus among children with acute respiratory infections in Kolkata, India, reveals a distinct seasonality of infection. J Med Microbiol 58:1616-1622

Anwar A, Anwar S, Ayub M, Nawaz F, Hyder S, Khan N, Malik I (2019) Climate change and infectious diseases: evidence from highly vulnerable countries. Iran J Public Health.: 2187-2195

Auler AC, Cássaro FAM, da Silva VO, Pires LF (2020) Evidence that high temperatures and intermediate relative humidity might favor the spread of COVID-19 in tropical climate: a case study for the most affected Brazilian cities. Sci Total Environ 729:139090

Bezirtzoglou C, Dekas K, Charvalos E (2011) Climate changes, environment and infection: facts, scenarios and growing awareness from the public health community within Europe. Anaerobe 17:337-340

Cai QC, Lu J, Xu QF, Guo Q, Xu DZ, Sun QW, Yang H, Zhao GM, Jiang QW (2007) Influence of meteorological factors and air pollution on the outbreak of severe acute respiratory syndrome. Public Health 121:258-265

Casadevall A (2020) Climate change brings the specter of new infectious diseases. J Clin Invest 130:553-555

Chan KH, Peiris JS, Lam SY, Poon LL, Yuen KY, Seto WH (2011) The effects of temperature and relative humidity on the viability of the SARS coronavirus. Adv Virol 2011:734690

Chen Y, Zheng M, Lv J, Shi T, Liu P, Wu Y, Feng W, He W, Guo P (2019) Interactions between ambient air pollutants and temperature on emergency department visits: analysis of varying-coefficient model in Guangzhou, China. Sci Total Environ 668:825-834

Chen C, Liu X, Wang X, Qu W, Li W, Dong L (2020) Effect of air pollution on hospitalization for acute exacerbation of chronic obstructive pulmonary disease, stroke, and myocardial infarction. Environ Sci Pollut Res Int 27:3384-3400

Chin AWH, Chu JTS, Perera MRA, Hui KPY, Yen H-L, Chan MCW, Peiris M, Poon LLM (2020) Stability of SARS-CoV-2 in different environmental conditions. The Lancet Microbe 1:e10

Ciencewicki J, Jaspers I (2007) Air pollution and respiratory viral infection. Inhal Toxicol 19:1135-1146

Coccia M (2020) Factors determining the diffusion of COVID-19 and suggested strategy to prevent future accelerated viral infectivity similar to COVID. Sci Total Environ 729:138474

Cui Y, Zhang ZF, Froines J, Zhao J, Wang H, Yu SZ, Detels R (2003) Air pollution and case fatality of SARS in the People's Republic of China: an ecologic study. Environ Health 2:15

Du Z, Wang L, Cauchemez S, Xu X, Wang X, Cowling BJ, Meyers LA (2020) Risk for transportation of coronavirus disease from Wuhan to other cities in China. Emerg Infect Dis 26:1049-1052

Frontera A, Martin C, Vlachos K, Sgubin G (2020) Regional air pollution persistence links to COVID-19 infection zoning. J Inf Secur 81:318 356

Guo Q, Xiong X, Liang F, Tian L, Liu W, Wang Z, Pan X (2019) The interactive effects between air pollution and meteorological factors on the hospital outpatient visits for atopic dermatitis in Beijing, China: a time-series analysis. J Eur Acad Dermatol Venereol 33: $2362-2370$
Holshue ML, DeBolt C, Lindquist S, Lofy KH, Wiesman J, Bruce H, Spitters C, Ericson K, Wilkerson S, Tural A, Diaz G, Cohn A, Fox L, Patel A, Gerber SI, Kim L, Tong S, Lu X, Lindstrom S, Pallansch MA, Weldon WC, Biggs HM, Uyeki TM, Pillai SK, Washington State 2019-nCoV Case Investigation Team (2020) First case of 2019 novel coronavirus in the United States. N Engl J Med 382:929-936

Horne BD, Joy EA, Hofmann MG, Gesteland PH, Cannon JB, Lefler JS, Blagev DP, Korgenski EK, Torosyan N, Hansen GI, Kartchner D, Pope CA 3rd (2018) Short-term elevation of fine particulate matter air pollution and acute lower respiratory infection. Am J Respir Crit Care Med 198:759-766

Hu Jianxiong HG, Tao L, Jianpeng X, Zuhua R, Lingchuan G, Weilin Z, Zhihua Z, Dexin G, Lihua Y, Donghua W, Lilian Z, Wenjun M (2020) Risk assessment of exported risk of COVID-19 from Hubei Province. Chinese Journal of Preventive Medicine 54:632-366

Hu W, Li Y, Han W, Xue L, Zhang W, Ma W, Bi P (2018) Meteorological factors and the incidence of mumps in Fujian province, China, 2005-2013: non-linear effects. Sci Total Environ 619620:1286-1298

Huang CH, Lin HC, Tsai CD, Huang HK, Lian IB, Chang CC (2017) The interaction effects of meteorological factors and air pollution on the development of acute coronary syndrome. Sci Rep 7:44004

Jiang Y, Wu XJ, Guan YJ (2020) Effect of ambient air pollutants and meteorological variables on COVID-19 incidence. Infect Control Hosp Epidemiol:1-11

Kesic MJ, Meyer M, Bauer R, Jaspers I (2012) Exposure to ozone modulates human airway protease/antiprotease balance contributing to increased influenza a infection. PLoS One 7:e35108

Lai CC, Shih TP, Ko WC, Tang HJ, Hsueh PR (2020) Severe acute respiratory syndrome coronavirus 2 (SARS-CoV-2) and coronavirus disease-2019 (COVID-19): the epidemic and the challenges. Int J Antimicrob Agents 55:105924

Liu J, Zhou J, Yao J, Zhang X, Li L, Xu X, He X, Wang B, Fu S, Niu T, Yan J, Shi Y, Ren X, Niu J, Zhu W, Li S, Luo B, Zhang K (2020a) Impact of meteorological factors on the COVID-19 transmission: a multi-city study in China. Sci Total Environ 726:138513

Liu K, Chen Y, Lin R, Han K (2020b) Clinical features of COVID-19 in elderly patients: a comparison with young and middle-aged patients. J Inf Secur 80:e14-e18

Mancia G, Rea F, Ludergnani M, Apolone G, Corrao G (2020) Reninangiotensin-aldosterone system blockers and the risk of Covid-19. N Engl J Med 382:2431-2440

Martelletti L, Martelletti P (2020) Air pollution and the novel Covid-19 disease: a putative disease risk factor. SN Compr Clin Med:1-5

McCormack MC, Belli AJ, Waugh D, Matsui EC, Peng RD, Williams DL, Paulin L, Saha A, Aloe CM, Diette GB, Breysse PN, Hansel NN (2016) Respiratory effects of indoor heat and the interaction with air pollution in chronic obstructive pulmonary disease. Ann Am Thorac Soc 13:2125-2131

Oliveiros B, Caramelo L, Ferreira NC, Caramelo F (2020) Role of temperature and humidity in the modulation of the doubling time of COVID-19 cases. medRxiv: 2020.03.05.20031872

Pani SK, Lin NH, RavindraBabu S (2020) Association of COVID-19 pandemic with meteorological parameters over Singapore. Sci Total Environ 740:140112

Pica N, Bouvier NM (2012) Environmental factors affecting the transmission of respiratory viruses. Curr Opin Virol 2:90-95

Prata DN, Rodrigues W, Bermejo PH (2020) Temperature significantly changes COVID-19 transmission in (sub)tropical cities of Brazil. Sci Total Environ 729:138862

Shek LP, Lee BW (2003) Epidemiology and seasonality of respiratory tract virus infections in the tropics. Paediatr Respir Rev 4:105-111

Siordia JA Jr (2020) Epidemiology and clinical features of COVID-19: a review of current literature. J Clin Virol 127:104357

Suhaimi NF, Jalaludin J, Latif MT (2020) Demystifying a possible relationship between COVID-19, air quality and meteorological factors: 
evidence from Kuala Lumpur. Malaysia Aerosol Air Qual Res 20: $1520-1529$

Tan J, Mu L, Huang J, Yu S, Chen B, Yin J (2005) An initial investigation of the association between the SARS outbreak and weather: with the view of the environmental temperature and its variation. J Epidemiol Community Health 59:186-192

Tobias A, Molina T (2020) Is temperature reducing the transmission of COVID-19 ? Environ Res 186:109553

Tosepu R, Gunawan J, Effendy DS, Ahmad OAI, Lestari H, Bahar H, Asfian P (2020) Correlation between weather and Covid-19 pandemic in Jakarta, Indonesia. Sci Total Environ 725:138436

van Doremalen N, Bushmaker T, Munster VJ (2013) Stability of Middle East respiratory syndrome coronavirus (MERS-CoV) under different environmental conditions. Euro Surveill 18:20590

Wang C, Horby PW, Hayden FG, Gao GF (2020a) A novel coronavirus outbreak of global health concern. Lancet 395:470-473

Wang M, Jiang A, Gong L, Luo L, Guo W, Li C, Zheng J, Li C, Yang B, Zeng J, Chen Y, Zheng K, Li H (2020b) Temperature significant change COVID-19 transmission in 429 cities. medRxiv: 2020.02.22.20025791

Wu Z, McGoogan JM (2020) Characteristics of and important lessons from the coronavirus disease 2019 (COVID-19) outbreak in China: summary of a report of 72314 cases from the Chinese Center for Disease Control and Prevention. JAMA 323:1239-1242

Wu F, Zhao S, Yu B, Chen YM, Wang W, Song ZG, Hu YA-O, Tao ZW, Tian JH, Pei YY, Yuan ML, Zhang YL, Dai FH, Liu Y, Wang QM, Zheng JJ, Xu L, Holmes EA-O, Zhang YZ (2020) A new coronavirus associated with human respiratory disease in China. Nature. 579: 265-269

Xie J, Zhu Y (2020) Association between ambient temperature and COVID-19 infection in 122 cities from China. Sci Total Environ 724:138201

Xu Z, Fau HW, Williams G, Fau WG, Clements ACA, Fau CA, Kan H, Fau KH, Tong S, Tong S (2013a) Air pollution, temperature and pediatric influenza in Brisbane, Australia. Environ Int 59:384-388
Xu Z, Hu W, Williams G, Clements AC, Kan H, Tong S (2013b) Air pollution, temperature and pediatric influenza in Brisbane, Australia. Environ Int 59:384-388

Yang BY, Qian Z, Howard SW, Vaughn MG, Fan SJ, Liu KK, Dong GH (2018) Global association between ambient air pollution and blood pressure: a systematic review and meta-analysis. Environ Pollut 235:576-588

Yao Y, Pan J, Liu Z, Meng X, Wang W, Kan H (2020) No association of COVID-19 transmission with temperature or UV radiation in Chinese cities. Eur Respir J 2000517

Yusuf S, Piedimonte G, Auais A, Demmler G, Krishnan S, Van Caeseele P, Singleton R, Broor S, Parveen S, Avendano L, Parra J, ChavezBueno S, Murguia De Sierra T, Simoes EA, Shaha S, Welliver R (2007) The relationship of meteorological conditions to the epidemic activity of respiratory syncytial virus. Epidemiol Infect 135:10771090

Zhao CX, Wang YQ, Wang YJ, Zhang HL, Zhao BQ (2014) Temporal and spatial distribution of PM2.5 and PM10 pollution status and the correlation of particulate matters and meteorological factors during winter and spring in Beijing. Huan Jing Ke Xue 35:418-427

Zhou P, Yang XL, Wang XG, Hu B, Zhang L, Zhang W, Si HR, Zhu Y, Li B, Huang CL, Chen HD, Chen J, Luo Y, Guo H, Jiang RD, Liu MQ, Chen Y, Shen XR, Wang X, Zheng XS, Zhao K, Chen QJ, Deng F, Liu LL, Yan B, Zhan FX, Wang YY, Xiao GF, Shi ZL (2020) A pneumonia outbreak associated with a new coronavirus of probable bat origin. Nature 579:270-273

Zhu Y, Xie J, Huang F, Cao L (2020) Association between short-term exposure to air pollution and COVID-19 infection: evidence from China. Sci Total Environ 727:138704

Publisher's note Springer Nature remains neutral with regard to jurisdictional claims in published maps and institutional affiliations. 